\title{
Synthesis of Amphiphilic Polystyrene-b-Poly(acrylic acid) Diblock Copolymers by Iodide-Mediated Radical Polymerization
}

\author{
Bingyi LI, Yan SHI, Wanchao ZHU, Zhifeng FU, ${ }^{\dagger}$ and Wantai YANG \\ Key Laboratory of Science and Technology of Controllable Chemical Reactions Ministry of Education, \\ Beijing University of Chemical Technology, Beijing 100029, China
}

(Received September 9, 2005; Accepted December 24, 2005; Published April 15, 2006)

\begin{abstract}
Amphiphilic polystyrene- $b$-poly(acrylic acid) (PS- $b$-PAA) diblock copolymers were prepared by iodide-mediated radical polymerization. Firstly, free radical polymerization of styrene was carried out with AIBN as initiater and iodoform as chain-transfer agent, giving iodine atom-ended polystyrene with controlled molecular weights. Secondly, tert-butyl acrylate ( $t \mathrm{BA})$ was polymerization using above obtained polystyrenes as macro-chain-transfer agents and PS- $b$-PtBA diblock copolymers with controlled molecular weights were obtained. Finally, amphiphilic PS- $b$-PAA diblock copolymers were prepared by hydrolysis of PS- $b$-P $t$ BA under the acid condition. The formation of PS- $b$-P $t$ BA and PS- $b$-PAA diblock copolymers was confirmed by the use of gel permeation chromatography and ${ }^{1} \mathrm{H}$ NMR spectroscopy. [DOI 10.1295/polymj.38.387]

KEY WORDS Living Radical Polymerization / Iodide-Mediated Radical Polymerization / Amphiphilic Block Copolymers / Styrene / tert-Butyl Acrylate /
\end{abstract}

Amphiphilic block copolymers have been extensively investigated both theoretically and practically in past few decades. Among them, block copolymers containing poly(methacrylic acid) (PMAA) and poly(acrylic acid) (PAA) segments have attracted increasing research interest because PMAA and PAA are weak polyelectrolytes and their dissociation degree can be governed by the $\mathrm{pH}$ and ionic strength of aqueous solution. ${ }^{1}$

Traditionally, well-defined block copolymers containing PMAA or PAA segments have been synthesized by sequential living anionic polymerization or group transfer polymerization of protected monomers, such as tert-butyl methacrylate ( $t \mathrm{BMA})$ and tert-butyl acrylate $(t \mathrm{BA})$, with subsequent elimination of protecting groups. ${ }^{2-9}$ For example, Teyssie et al. ${ }^{2}$ prepared AB- and ABA-type block copolymers by sequential anionic polymerization of styrene and $t \mathrm{BA}$ in the presence of $\mathrm{LiCl}$ in $\mathrm{THF}$ at $-78^{\circ} \mathrm{C}$, followed by hydrolysis using $p$-toluene sulfonic acid as catalyst. However, the anionic polymerization or group transfer polymerization need to be carried out under rigorous conditions such as in high-vacuum, highly purified monomers and solvents, making large-scale production by these processes impractical. Recent progress in controlled radical polymerization, especially nitroxide-mediated radical polymerization (NMRP),${ }^{10}$ atom transfer radical polymerization (ATRP), ${ }^{11,12}$ and reversible addition-fragmentation chain transfer polymerization (RAFT), ${ }^{13}$ opens a new channel to prepare welldefined block copolymers at much mild reaction conditions. Block copolymers containing PMAA or PAA segments have been successfully synthesized using ATRP, ${ }^{14-22}$ RAFT, ${ }^{23,24}$ and NMRP ${ }^{25,26}$ techniques. The so-called iniferter-based living radical polymerization was also employed for the synthesis of block copolymers containing PMAA segment. ${ }^{27}$

Iodide-mediated living radical polymerization was discovered by Tatemoto et al. in $1984 .{ }^{28}$ Degenerative transfer mechanism for this polymerization was first proposed by Matyjaszewski et al..$^{29-31}$ in 1995, and later this polymerization was investigated in detail by Fukuda et $a l .{ }^{32}$ In this system, a conventional radical initiator is needed together with the specific transfer agent, and a great advantage of the reversible transfer technique is that the experimental conditions can be very close to conventional ones, in terms of temperature, concentrations and processes. The synthesis of block copolymers using iodide-mediated radical polymerization in bulk and mini-emulsion systems has been described. ${ }^{29,33-35}$ Nevertheless, to the best of our knowledge, the preparation of PS- $b$-PAA amphiphilic block copolymer using this technique has not been reported. Because the reaction conditions for iodide-mediated radical polymerization are very close to conventional ones and there is no use of catalyst as in ATRP which is need to be removed or expensive agent as in NMRP and RAFT, we herein reported the synthesis of polystyrene- $b$-poly(tert-butyl acrylate) (PS- $b$-P $t$ BA) diblock copolymer via iodidemediated radical polymerization, in which styrene was used as the first monomer to prepare the macrotransfer agent with iodine atom terminal group and $t \mathrm{BA}$ as the second monomer. The amphiphilic diblock

${ }^{\dagger}$ To whom correspondence should be addressed (E-mail: fuzf@mail.buct.edu.cn). 
copolymer, PS- $b$-PAA, was then obtained through hydrolysis of (PS- $b-\mathrm{P} t \mathrm{BA})$ under acid condition.

\section{EXPERIMENTAL}

\section{Materials}

Styrene (Polymerization grade, Yanshan Petrochemical Co.) and $t$ BA (Analytical grade, Shanghai Chemicals plant) were dried over anhydrous $\mathrm{MgSO}_{4}$, then distilled under reduced pressure and stored in brown glass bottles at $-15^{\circ} \mathrm{C}$. $\alpha, \alpha^{\prime}$-Azobisisobutyronitrile (AIBN, 98\%, Fluka) was recrystallized from ethanol. Iodoform (Analytical grade, Beijing Chemicals plant) and all other reagents were used without further purification.

\section{Synthesis of Macro-transfer Agent (PS-I)}

In a typical experiment, $0.1642 \mathrm{~g}(1.0 \mathrm{mmol})$ of AIBN, $1.9743 \mathrm{~g}$ of iodoform $(5.0 \mathrm{mmol})$ and $25.01 \mathrm{~g}$ of styrene $(240.0 \mathrm{mmol})$ and $27.5 \mathrm{~mL}$ of benzene were added to a $100 \mathrm{~mL}$ dry round-bottomed flask equipped with a magnetic stirrer. After five freeze-pump-thaw cycles, the flask was placed in an oil bath thermostated at $65^{\circ} \mathrm{C}$. At definite time intervals, portions of the sample were withdrawn from the flask using argonfilled gas-tight syringes to determine monomer conversions and molecular weights. The polymerization was stopped by pouring the reaction mixture into a large amount of cold methanol and the precipitated polystyrene was obtained by filtration.

\section{Synthesis of Diblock Copolymer (PS-b-PtBA)}

In a typical experiment, $0.0328 \mathrm{~g}$ of AIBN $(0.20$ $\mathrm{mmol}), 2.11 \mathrm{~g}$ of PS-I $\left(1.0 \mathrm{mmol}, M_{\mathrm{n}, \mathrm{GPC}}=2100\right.$, $\left.M_{\mathrm{w}} / M_{\mathrm{n}}=1.42\right), 5.00 \mathrm{~g}$ of $t \mathrm{BA}(39 \mathrm{mmol})$ and 15.0 $\mathrm{mL}$ of benzene were added to a $100 \mathrm{~mL}$ dry roundbottomed flask equipped with a magnetic stirrer. After five freeze-pump-thaw cycles, the flask was placed in an oil bath thermostated at $65{ }^{\circ} \mathrm{C}$. At definite time intervals, portions of the sample were withdrawn from the flask using argon-filled gas-tight syringe to determine monomer conversions and molecular weights. The polymerization was stopped by pouring the reaction mixture into a large amount of cold methanol and the precipitated block copolymer was obtained by filtration.

\section{Hydrolysis of PS- $b-P t B A$}

One gram of PS- $b$-P $t$ BA block copolymer was dissolved in $80 \mathrm{~mL}$ dioxane, and then $10 \mathrm{~mL}$ of $\mathrm{HCl}$ $(5 \mathrm{M})$ was added slowly under stirring to prevent the precipitation of the block copolymer. After being heated under reflux condition for $48 \mathrm{~h}$, the solution was filtered to remove insoluble impurities. The filtrate was concentrated by rotary evaporator and the white powdered polymer was recovered by precipitation in cyclohexane.

\section{Characterization}

Monomer conversion was obtained gravimetrically. Molecular weights and molecular weight distributions of macro-chain-transfer agent and block copolymers were measured using gel permeation chromatography (GPC), on a system equipped with a Waters 515 pump, three columns (Styragel HR1, Styragel HR3 and Styragel HT4) and a 2410 differential refractometer detector. The eluent was THF and the flow rate was $1 \mathrm{~mL} / \mathrm{min}$. Narrow polystyrene standards were used to generate the calibration curve. ${ }^{1} \mathrm{H}$ NMR spectra were obtained using a Bruker AV600-MHz NMR spectrometer. $\mathrm{CDCl}_{3}$ or $\mathrm{CD}_{3} \mathrm{COCD}_{3}$ was used as solvent. The FT-IR spectra were recorded at room temperature on a Nicolet Nexus-670 spectrometer using $\mathrm{KBr}$ tablets.

\section{RESULTS AND DISCUSSION}

The amphiphilic diblock copolymer PS- $b$-PAA was synthesized in three steps (Scheme 1). Firstly, free radical polymerization of styrene was carried out with AIBN as initiator and iodoform as chain-transfer agent to prepare iodine atom-ended polystyrene, PSI. Secondly, free radical polymerization of $t \mathrm{BA}$ was carried out using the above obtained iodine atomended polystyrene obtained above as macro-chaintransfer agent to prepare PS- $b$-P $t$ BA block copolymer. Finally, amphiphilic diblock copolymer PS- $b$-PAA was obtained by hydrolysis of PS- $b$-P $t$ BA under the acid condition.

\section{Free Radical Polymerization of Styrene with Iodoform} as Chain-Transfer Agent

Styrene was polymerized in benzene at $65^{\circ} \mathrm{C}$ with the molar ratio of iodoform to AIBN to be 5:1. By

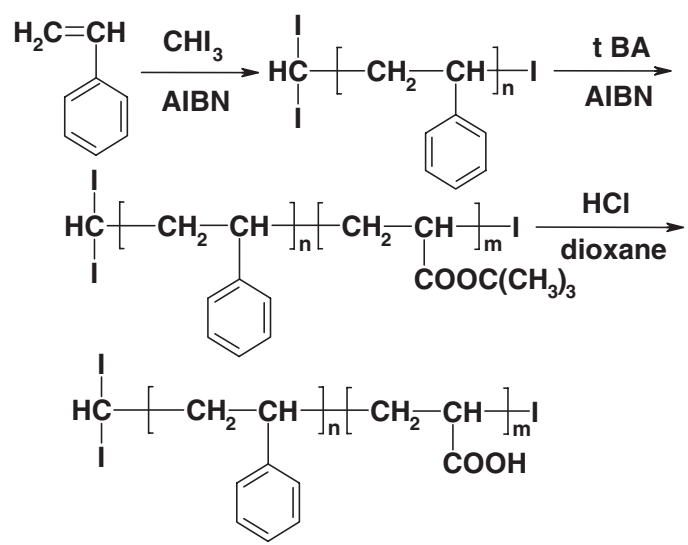

Scheme 1. Synthesis of amphiphilic diblock copolymer PS- $b$ PAA. 


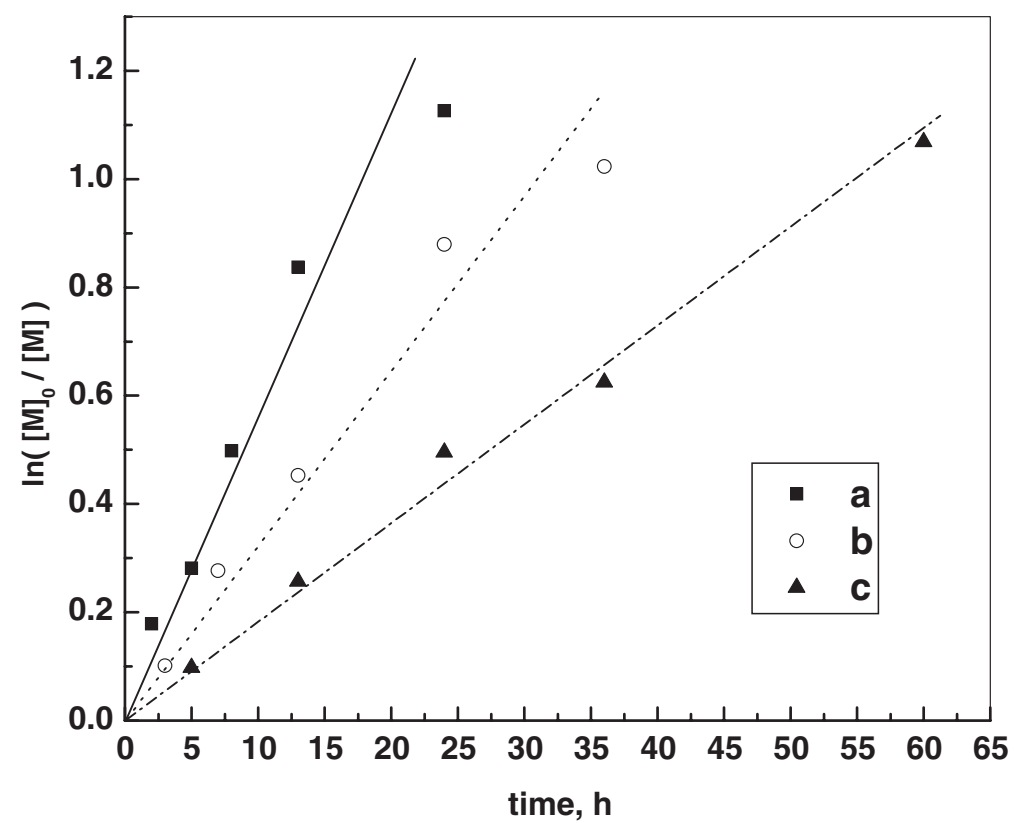

Figure 1. First-order plots for the polymerization of styrene in benzene at $65^{\circ} \mathrm{C}$. Reaction conditions: $[\mathrm{St}]=4.61 \mathrm{M}$. (a) $[\mathrm{St}]:[\mathrm{CHI} 3]$ : $[\mathrm{AIBN}]=240: 5: 1$. (b) $[\mathrm{St}]:\left[\mathrm{CHI}_{3}\right]:[\mathrm{AIBN}]=480: 5: 1$. (c) $[\mathrm{St}]:\left[\mathrm{CHI}_{3}\right]:[\mathrm{AIBN}]=960: 5: 1$.

varying the molar ratio of styrene to iodoform, three experiments were carried out. As shown in Figure 1, the logarithmic conversion data, $\ln \left([\mathrm{M}]_{0} /[\mathrm{M}]\right)([\mathrm{M}]$ is the monomer concentration at time $t$ ), plotted against time $t$, gave straight lines passing through the origin, which shows constant concentrations of the growing species during the polymerizations. Furthermore, the reason why polymerization rate decreased with the increase of the molar ratio of styrene to iodoform was that the concentration of AIBN decreased at the same time.

Figure 2 shows the number-average molecular weights $\left(M_{\mathrm{n}}\right)$, the polydispersity indexes $\left(M_{\mathrm{w}} / M_{\mathrm{n}}\right)$ and molecular weight distribution curves of the polystyrenes obtained at different $\mathrm{CHI}_{3}$ concentrations. The molecular weight distribution curves were unimodal throughout the polymerizations, although the polydispersity indexes were broader than those for other controlled free radical polymerization methods, such as ATRP and RAFT. The polydispersity indexes of the polystyrenes obtained at higher $\mathrm{CHI}_{3}$ concentrations were relatively low.

The number-average molecular weights increased in direct proportional to monomer conversion, and agreed well with the theoretical ones, $M_{\mathrm{n}, \mathrm{th}}$, which were calculated from the amount of the consumed monomer $(\Delta[\mathrm{St}])$, the amount of iodoform added $\left(\left[\mathrm{CHI}_{3}\right]\right)$ and the molecular weight of styrene (104) using the following equation.

$$
M_{\mathrm{n}, \mathrm{th}}=\Delta[\mathrm{St}] /\left[\mathrm{CHI}_{3}\right] \times 104
$$

The terminal structures of the obtained polystyrenes were then analyzed by ${ }^{1} \mathrm{H}$ NMR spectroscopy.
Figure 3 shows the spectrum of one polystyrene prepared in benzene at $65^{\circ} \mathrm{C}([\mathrm{St}]=4.61 \mathrm{M}$; $[\mathrm{St}]$ : $\left[\mathrm{CHI}_{3}\right]:[\mathrm{AIBN}]=240: 5: 1$; polymerization time, $15 \mathrm{~h}$; conversion, $\left.45.0 \% ; M_{\mathrm{n}, \mathrm{GPC}}=2100, M_{\mathrm{w}} / M_{\mathrm{n}}=1.42\right)$. Besides the large absorptions of the repeating units of styrene, there are characteristic signals originating from $\mathrm{CHI}_{3}$. The methine proton (a) at the $\alpha$-end of polymer chain, which was derived from $\mathrm{CHI}_{3}$, was seen at $4.30 \mathrm{ppm}$. The peaks at 4.51 to $4.65 \mathrm{ppm}$ were ascribed to the methine proton (b) at the $\omega$-end adjacent to the iodine atom. ${ }^{36}$ Furthermore, the ratio of $I_{\mathrm{a}} / I_{\mathrm{b}}$ was $1: 1.18$, which was close to $1: 1$, where $I_{\mathrm{a}}$ and $I_{\mathbf{b}}$ are the integral values of methine proton at the $\alpha$-end derived from $\mathrm{CHI}_{3}$ and that at the $\omega$-end adjacent to the iodine atom, respectively, indicating that the obtained polystyrene indeed had $\mathrm{CHI}_{3}$ moiety at one end and an iodine atom at the other end.

The molecular weight of this polystyrene sample was determined from the peak intensity ratio of the methine proton adjacent to the iodine atom at $\omega$-end to the aromatic protons of main chain $\left(I_{\mathbf{c}} / 5 I_{\mathbf{b}}\right)$. Taking into the end groups from $\mathrm{CHI}_{3}$, the number-average molecular weight was 2200 , which was in excellent agreement with the value $\left(M_{\mathrm{n}, \mathrm{GPC}}=2100\right)$ from GPC calibrated against standard polystyrene samples. This result further confirmed that there was an iodine atom at the $\omega$-end for every polystyrene chain.

Free Radical Polymerization of tert-Butyl Acrylate with Polystyrene Obtained Above as Macro-ChainTransfer Agent

Compared with 1-phenylethyl iodide, the iodine atom at the $\omega$-end of polystyrene obtained above 

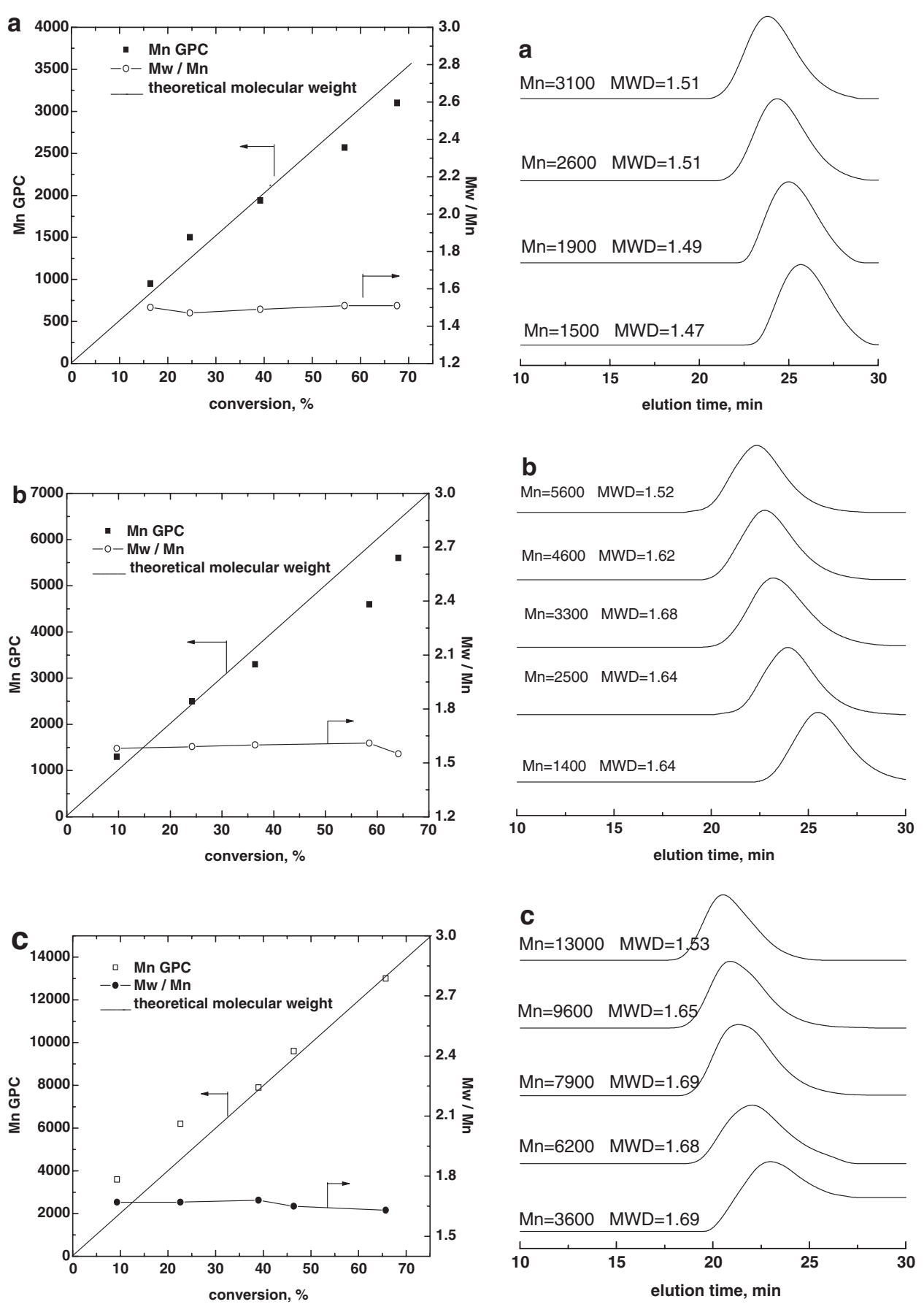

Figure 2. $M_{\mathrm{n}}, M_{\mathrm{w}} / M_{\mathrm{n}}$ and molecular weight distribution curves of polystyrenes obtained with different concentrations of $\mathrm{CHI}_{3}$ in benzene at $65^{\circ} \mathrm{C}$. For reaction conditions, see Figure 1.

had the same chemical environment. Therefore, it can be used as macro-chain-transfer agent to control free radical polymerization, which have been reported by Matyjaszewski et al. ${ }^{31}$ and Farcet et al. ${ }^{33}$ In this study, two polystyrenes with different molecular weights were used in the free radical polymerization of $t \mathrm{BA}$. Their number-average molecular weights $\left(M_{\mathrm{n}}\right)$ and molecular weight distributions $\left(M_{\mathrm{w}} / M_{\mathrm{n}}\right)$ were 2100 and 1.42 , and 6600 and 1.42 , respectively. The narrow molecular weight distributions were attributed to the precipitation treatment of crude products in methanol.
Figure 4 shows the kinetic plot of $\ln \left([\mathrm{M}]_{0} /[\mathrm{M}]\right) v s$. time for $t \mathrm{BA}$ polymerization with AIBN as initiator and polystyrenes obtained above as macro-chain-transfer agents. The straight lines indicate that the polymerization proceeded with an approximately constant concentration of active species, therefore the contribution of termination reactions could be neglected.

GPC traces of the products obtained at different monomer conversions are shown in Figure 5. It can be seen that GPC curves were unimodal throughout the polymerizations and the molecular weight shifted 


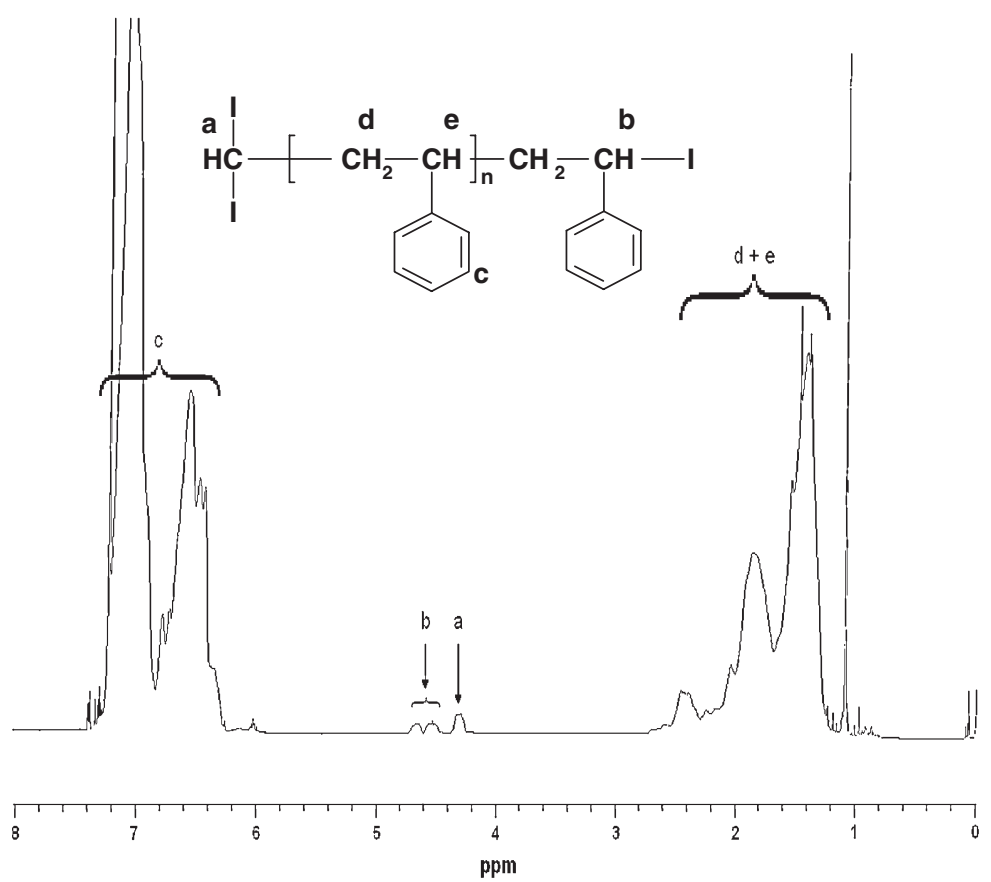

Figure 3. ${ }^{1} \mathrm{H}$ NMR spectrum of polystyrene $\left(M_{\mathrm{n}, \mathrm{GPC}}=2100\right)$ prepared in benzene at $65^{\circ} \mathrm{C}$. Solvent: $\mathrm{CDCl}_{3}$. For detailed preparation condition, see the text.

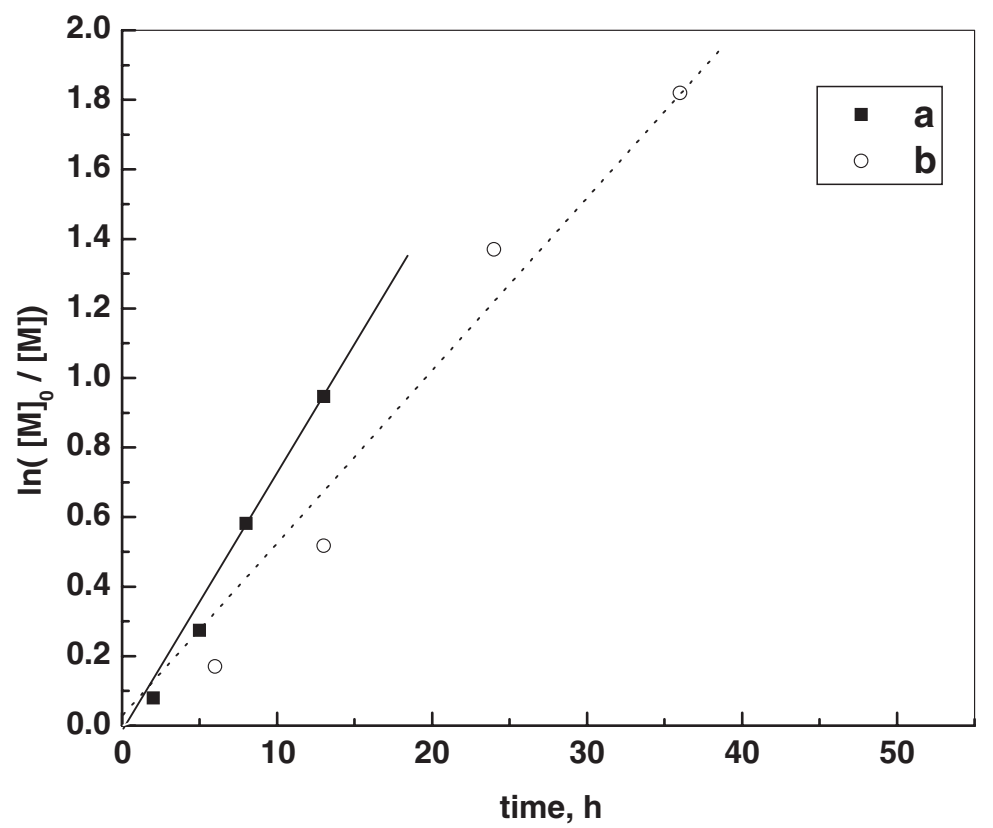

Figure 4. First-order plots for the polymerization of $t \mathrm{BA}$ in benzene at $65^{\circ} \mathrm{C}$. Reaction conditions: $[t \mathrm{BA}]=1.7 \mathrm{M}$. (a) $M_{\mathrm{n}, \mathrm{GPC}}$ and $M_{\mathrm{w}} / M_{\mathrm{n}}$ of PS-I were 2100 and 1.42 , respectively. [tBA]:[PS-I]:[AIBN] $=195: 5: 1$. (b) $M_{\mathrm{n}, \mathrm{GPC}}$ and $M_{\mathrm{w}} / M_{\mathrm{n}}$ of PS-I were 6600 and 1.42 , respectively. [ $t \mathrm{BA}]:[\mathrm{PS}-\mathrm{I}]:[\mathrm{AIBN}]=390: 5: 1$.

to higher molecular weights without any trace of the polystyrene macro-chain-transfer agents, indicating successful formation of PS- $b$-P $t$ BA block copolymers. Furthermore, the number-average molecular weights of PS- $b$-P $t$ BA block copolymers increased in direct proportional to monomer conversion, although their polydispersities were somewhat broader than those of polystyrene macro-chain-transfer agents. In addi- tion, no PtBA homopolymer was detected by GPC. This may be because the chain-transfer constant of PS-I was large enough and only a little amount of $\mathrm{P} t \mathrm{BA}$ homopolymer was produced.

Figure 6 shows the ${ }^{1} \mathrm{H}$ NMR spectrum of the product of $t \mathrm{BA}$ free radical polymerization with AIBN as initiator and PS-I as macro-chain-transfer agent. It can be seen that the signal at 4.51-4.65 ppm correspond- 

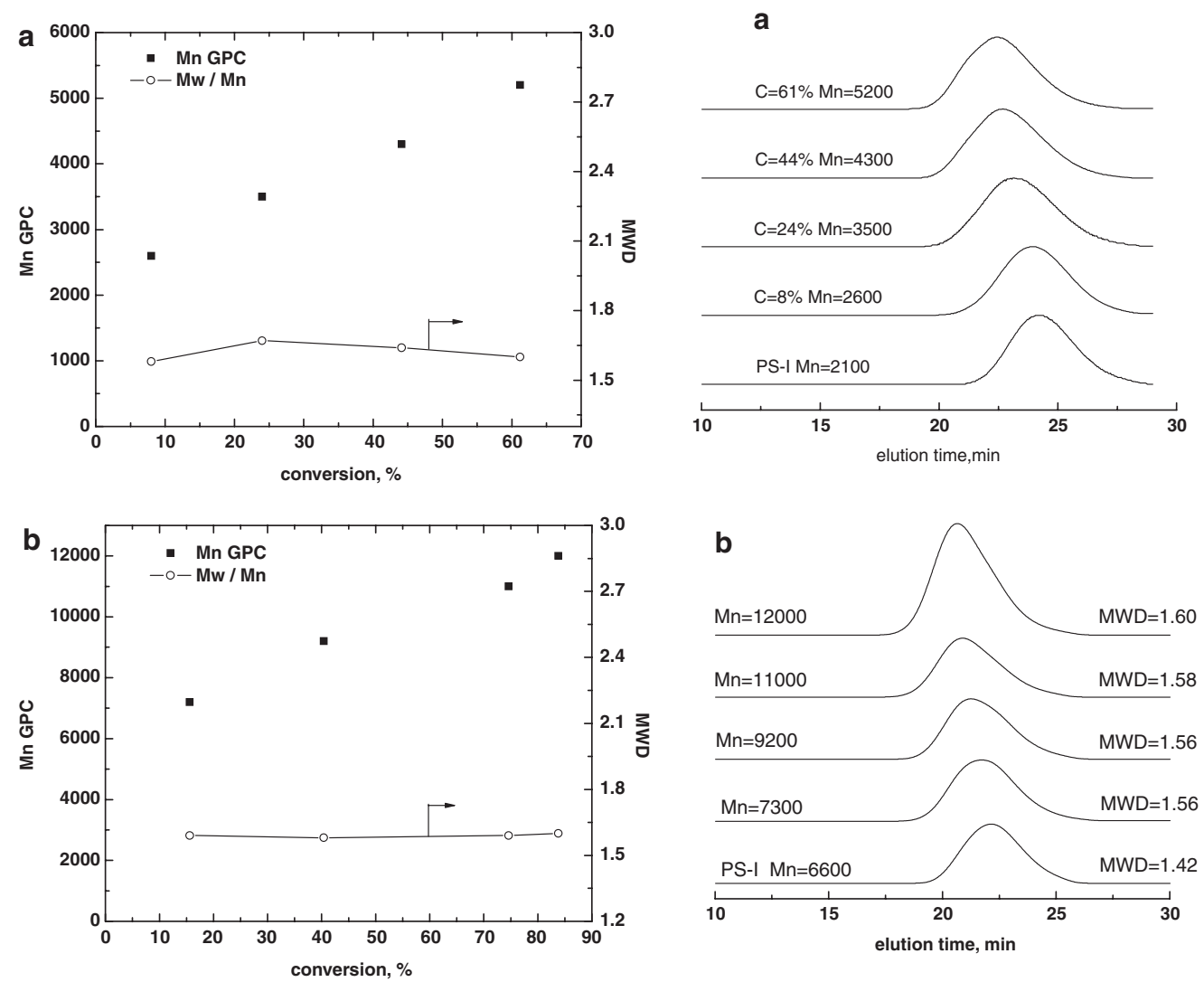

Figure 5. $M_{\mathrm{n}}, M_{\mathrm{w}} / M_{\mathrm{n}}$ and molecular weight distribution curves of PS- $b$-P $t \mathrm{BA}$ block copolymers obtained at different monomer conversions in benzene at $65^{\circ} \mathrm{C}$. For reaction conditions, see Figure 4 .

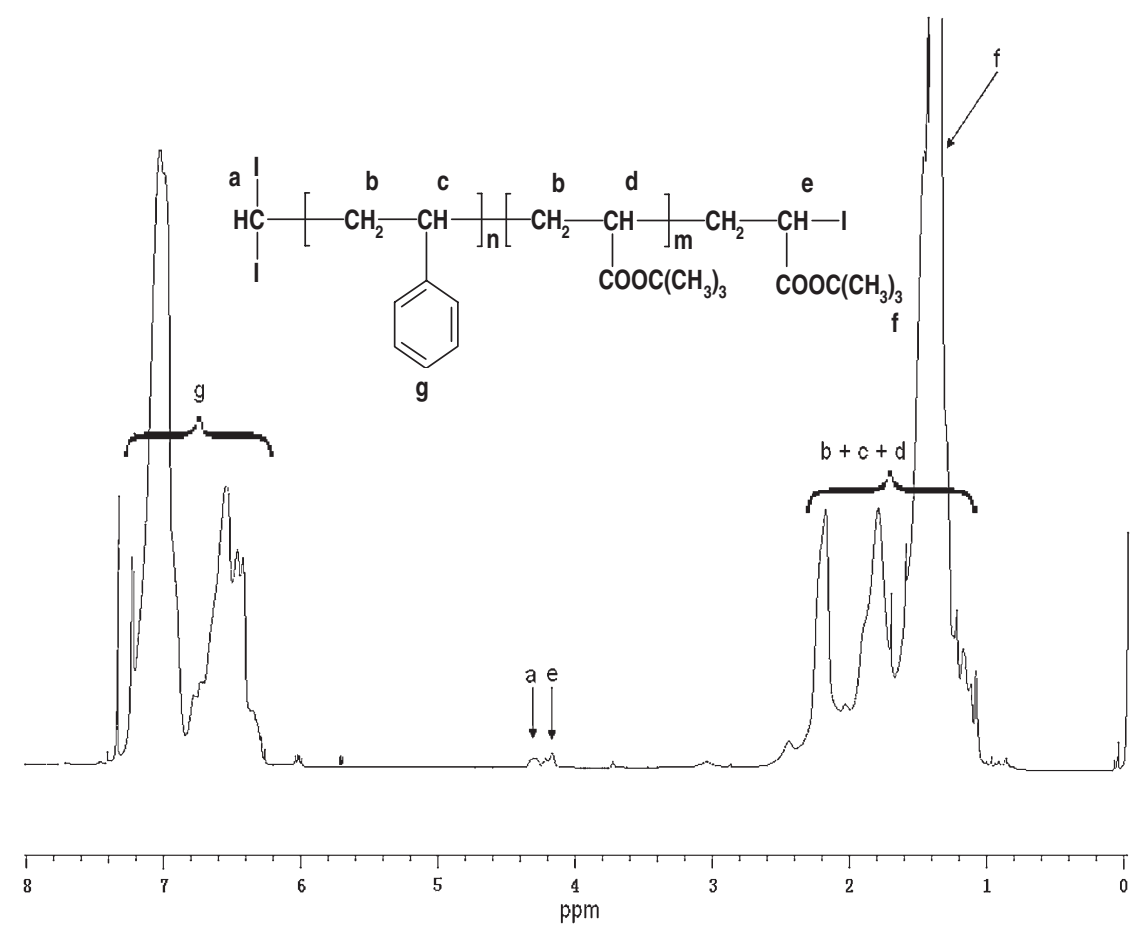

Figure 6. ${ }^{1} \mathrm{H}$ NMR spectrum of PS- $b$-PtBA diblock copolymer. Solvent: $\mathrm{CDCl}_{3}$.

ing to the methine proton of polystyrene adjacent to the iodine atom disappeared completely, while a new signal at $4.21 \mathrm{ppm}$ appeared, which was attribut- ed to the methine proton of $\mathrm{P} t \mathrm{BA}$ segment adjacent to the iodine atom. This shows that all PS-I took part in the chain-transfer reaction. In addition, the signal at 


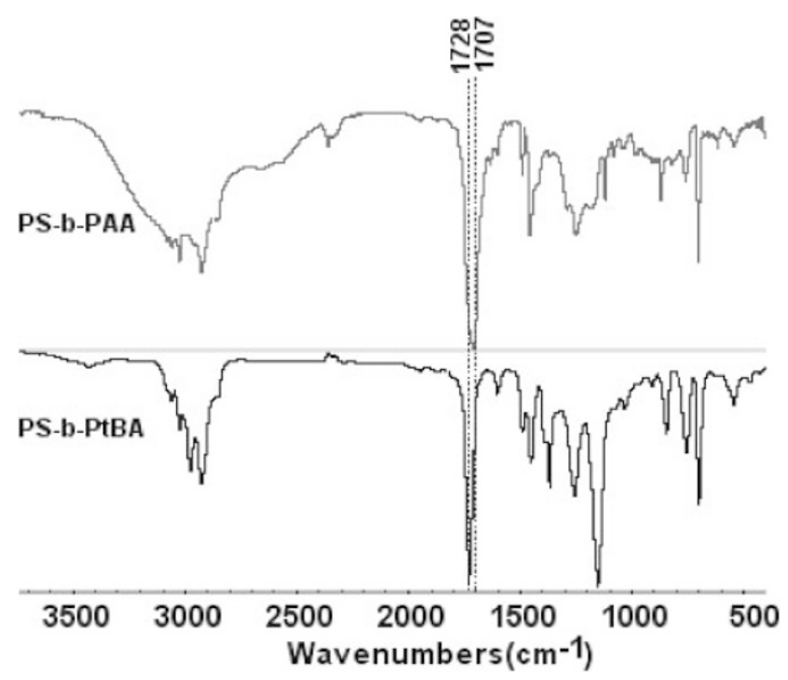

Figure 7. The FT-IR spectra of diblock copolymer PS- $b$-P $t$ BA and PS- $b$-PAA.

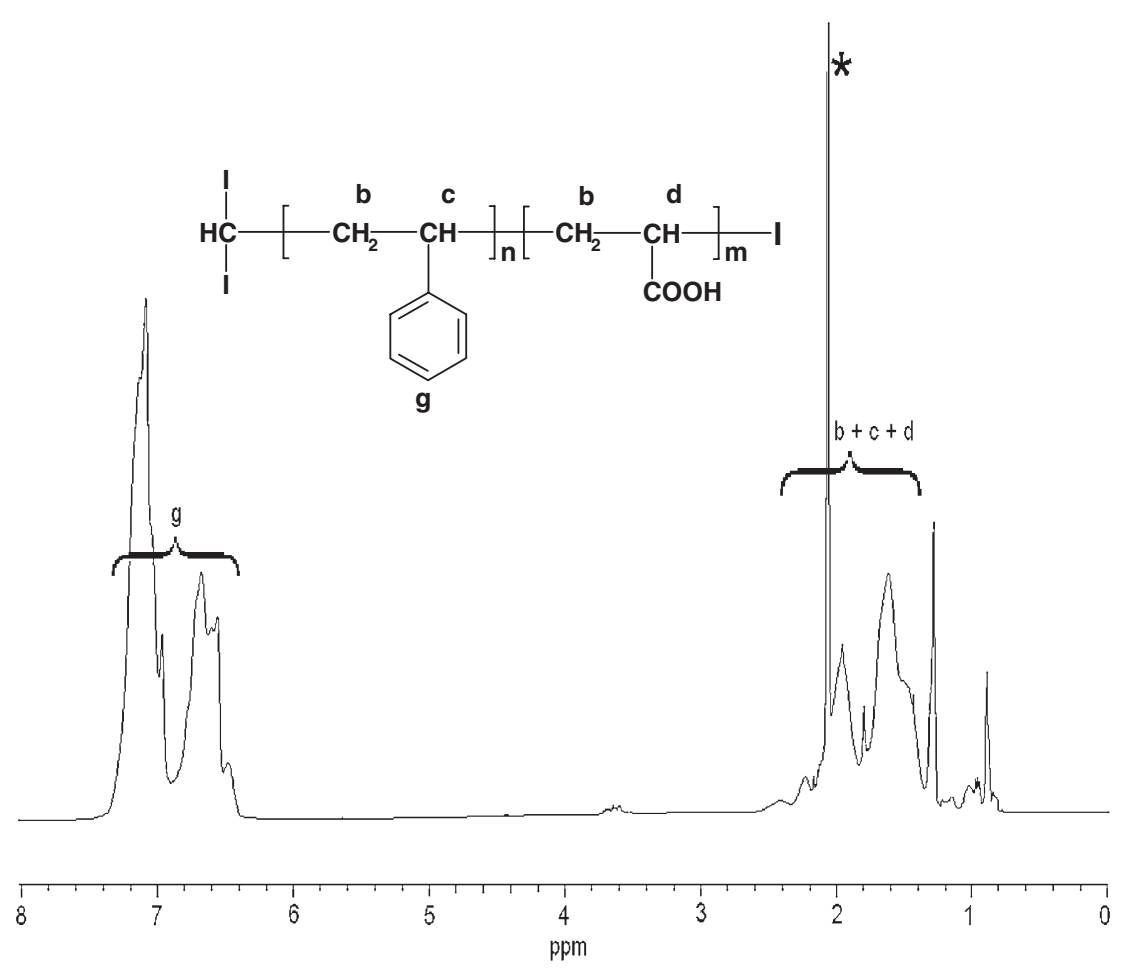

Figure 8. ${ }^{1} \mathrm{H}$ NMR spectrum of amphiphilic diblock copolymer PS- $b$-PAA. Solvent: $\mathrm{CD}_{3} \mathrm{COCD}_{3}$. ${ }^{*}$ Due to water in the deuterated $\mathrm{CD}_{3} \mathrm{COCD}_{3}$. For detailed preparation condition, see the text.

$4.30 \mathrm{ppm}$ corresponding to the methine proton at the $\alpha$-end of polymer chain, which was derived from $\mathrm{CHI}_{3}$, still existed. Furthermore, the ratio of $I_{\mathrm{a}} / I_{\mathrm{e}}$ was about 1.0, where $I_{\mathrm{a}}$ and $I_{\mathrm{e}}$ are the integral values of methine proton at the $\alpha$-end derived from $\mathrm{CHI}_{3}$ and that at the $\omega$-end of $\mathrm{P} t \mathrm{BA}$ adjacent to the iodine atom, respectively, indicating that well-defined PS- $b$-P $t$ BA diblock copolymer was successfully synthesized.

\section{Hydrolysis of PS-b-PtBA Diblock Copolymer}

Cleavage of the tert-butyl ester groups was achieved by the PS- $b$-P $t$ BA diblock copolymers being treat- ed in dioxane with $\mathrm{HCl}$ at reflux temperature. IR spectra of PS- $b$-P $t$ BA diblock copolymer and its hydrolyzed product PS- $b$-PAA are shown in Figure 7. It can be seen that the absorption at $1728 \mathrm{~cm}^{-1}$ disappeared completely and a new absorption at $1707 \mathrm{~cm}^{-1}$ due to the carboxyl group of PAA block appeared. Figure 8 shows the ${ }^{1} \mathrm{H}$ NMR spectrum of hydrolysis product. The signal at $1.42 \mathrm{ppm}$, resulting from the tert-butyl protons of the $\mathrm{P} t \mathrm{BA}$ block, disappeared almost completely, indicating that the PS- $b-\mathrm{P} t \mathrm{BA}$ diblock copolymer had successfully transformed into PS- $b$-PAA amphiphilic diblock copolymer. 


\section{CONCLUSIONS}

Free radical polymerization of styrene was carried out with AIBN as initiator and iodoform as chaintransfer agent, giving iodine atom-ended polystyrene with controlled molecular weights. tert-Butyl acrylate was then polymerized using polystyrenes obtained above as macro-chain-transfer agents and PS- $b$-P $t$ BA diblock copolymers with controlled molecular weights were obtained. The number-average molecular weights of PS- $b$-P $t$ BA diblock copolymers increased in direct proportional to monomer conversion, and the molecular weights shifted to higher molecular weight direction without any trace of the polystyrene macro-chain-transfer agents. In addition, no PtBA homopolymer was detected by GPC. The PS- $b$-PAA amphiphilic diblock copolymers were successfully obtained by hydrolysis of PS- $b$-P $t$ BA under acid condition.

\section{REFERENCES}

1. H. Mori and A. H. E. Müller, Prog. Polym. Sci., 28, 1403 (2003).

2. J.-P. Hautekeer, S. K. Varshney, R. Fayt, C. Jacobs, R. Jerome, and P. Teyssie, Macromolecules, 23, 3893 (1990).

3. H. Zhang, H. Ishikawa, M. Ohata, T. Kazama, Y. Isono, and T. Fujimoto, Polymer, 33, 828 (1992).

4. C. Ramireddy, Z. Tuzar, K. Prochazka, S. E. Webber, and P. Munk, Macromolecules, 25, 2541 (1992).

5. S. K. Varshney, C. Jacobs, J. P. Hautekeer, P. Bayard, R. Jerome, R. Fayt, and P. Teyssie, Macromolecules, 24, 4997 (1991).

6. E. Ruckenstein and H. Zhang, Macromolecules, 31, 9127 (1998).

7. S. P. Rannard, N. C. Billingham, S. P. Armes, and J. Mykytiuk, Eur. Polym. J., 29, 407 (1993).

8. J. Kriz, B. Masar, H. Pospisil, J. Plestil, Z. Tuzar, and M. A. Kiselev, Macromolecules, 29, 7853 (1996).

9. W. J. Choi, Y. B. Kim, S. K. Kwon, K. T. Lim, and S. K. Choi, J. Polym. Sci., Part A: Polym. Chem., 30, 2143 (1992).

10. C. J. Hawker, A. W. Bosman, and E. Harth, Chem. Rev., 101, 3661 (2001).

11. K. Matyjaszewski and J. Xia, Chem. Rev., 101, 2921 (2001).

12. M. Kamigaito, T. Ando, and M. Sawamoio, Chem. Rev., 101, 3689 (2001).

13. J. Chiefari, Y. K. Chong, F. Ercole, J. Krstina, T. P. Le, G.
Moad, E. Rizzardo, and S. H. Thang, Macromolecules, 31, 5559 (1998).

14. K. A. Davis and K. Matyjaszewski, Macromolecules, 33, 4039 (2000).

15. K. A. Davis, B. Charleux, and K. Matyjaszewski, J. Polym. Sci., Part A: Polym. Chem., 38, 2274 (2000).

16. S. Lu, Q.-L. Fan, S.-Y. Liu, S.-J. Chua, and W. Huang, Macromolecules, 35, 9875 (2002).

17. Y. Liu, L. Wang, and C. Pan, Macromolecules, 32, 8301 (1999).

18. C. Burguiere, S. Pascual, C. Bui, J. P. Vairon, B. Charleux, K. A. Davis, K. Matyjaszewski, and I. Betremieux, Macromolecules, 34, 4439 (2001).

19. C. Burguiere, C. Chassenieux, and B. Charleux, Polymer, 44, 509 (2003).

20. G. Wang and D. Yan, J. Appl. Polym. Sci., 82, 2381 (2001).

21. P. Ravi, C. Wang, K. C. Tam, and L. H. Gan, Macromolecules, 36, 173 (2003).

22. Q. Ma and K. L. Wooley, J. Polym. Sci., Part A: Polym. Chem., 38, 4805 (2000).

23. Y. K. Chong, T. P. T. Le, G. Moad, E. Rizzardo, and S. H. Thang, Macromolecules, 32, 2071 (1999).

24. N. Gaillard, A. Guyot, and J. Claverie, J. Polym. Sci., Part A: Polym. Chem., 41, 684 (2003).

25. N. A. Listigovers, M. K. Georges, P. G. Odell, and B. Keoshkerian, Macromolecules, 29, 8992 (1996).

26. D. Benoit, V. Chaplinski, R. Braslau, and C. J. Hawker, J. Am. Chem. Soc., 121, 3904 (1999).

27. S.-H. Qin and K.-Y. Qiu, J. Polym. Sci., Part A: Polym. Chem., 39, 1450 (2001).

28. M. Oka and M. Tatemoto, Ed., "Contemporary Topics in Polymer Science, Vol. 4,” Plenum Press, New York, 1984, p. 763.

29. J.-S. Wang, S. Gaynor, and K. Matyjaszewski, Polym. Prepr. (Am. Chem. Soc., Div. Polym. Chem.), 36, 465 (1995).

30. K. Matyjaszewski, S. Gaynor, and J. Wang, Macromolecules, 28, 2093 (1995).

31. S. Gaynor, J. Wang, and K. Matyjaszewski, Macromolecules, 28, 8051 (1995).

32. A. Goto, K. Ohno, and T. Fukuda, Macromolecules, 31, 2809 (1998).

33. C. Farcet, M. Lansalot, R. Pirri, J. P. Vairon, and B. Charleux, Macromol. Rapid. Commun., 21, 921 (2000).

34. M. Lansalot, C. Farcet, B. Charleux, and J. P. Vairon, Macromolecules, 32, 7354 (1999).

35. M. Teodorescu, M. Dimonie, C. Draghici, and G. Vasilievici, Polym. Int., 53, 1987 (2004).

36. Y. Kotani, M. Kamigaito, and M. Sawamoto, Macromolecules, 32, 2420 (1999). 